\title{
Shear Test on Reinforced Clay
}

\author{
Amin Chegenizadeh ${ }^{1,}$ a , Prof. Hamid Nikraz ${ }^{2, b}$ \\ ${ }^{1} \mathrm{PhD}$ candidate, Department of Civil Engineering, Curtin University of Technology, Perth, \\ Australia; Tel: +61-413165961; Fax: +61 892662681 \\ ${ }^{2}$ Prof. Hamid Nikraz, Head of the Department of Civil Engineering, Curtin University of \\ Technology, Perth, Australia; Tel: +61 89266 7573; Fax: +61 892662681 \\ a Email: amin.chegenizadeh@postgrad.curtin.edu.au, \\ b Email: H.Nikraz@curtin.edu.au
}

\begin{abstract}
Composite soils have been widely used in civil engineering applications, especially in slopes, embankment dam and landfills. This paper aims to investigate effect of fiber inclusion on shear stress of composite soil (i.e. clay composite). A series of laboratory direct shear tests carried out to evaluate fiber effect on strength behavior of composite clay. Clay was selected as soil part of the composite and plastic fiber was used as reinforcement. The fiber parameters differed from one test to another, as fiber length were changed from $20 \mathrm{~mm}$ to $65 \mathrm{~mm}$ and fiber content were varied from $0.7 \%$ and $2 \%$.Normal stress kept constant at 150 kpa. For each test, stress_displacement graph derived and the results were compared. The results proved that inclusion of fiber affected shear stress behaviour of clay composite so that increasing in fiber content and length caused increasing in shear stress.
\end{abstract}

Keywords: Direct shear, Reinforced, Fiber, Clay

\section{INTRODUCTION}

The direct shear test is one of the oldest strength tests for soils. In this study, a direct shear device will be used to determine the shear strength of a fiber reinforced soil. Applications of soil strengthening or stabilization range from the mitigation of complex slope hazards to enhancing the subgrade stability. Together with the many applications for improving soil, there are several widely varied methods. The mixing of randomly oriented fibers to a soil sample may be considered same as other admixtures used to stabilize soil. Material used to make fibers for reinforcement may be obtained from paper, metal, nylon, polyester and other materials having widely varied physical properties. There have been numerous past papers published on the topic of fiber strengthening of soils. Examples include Lee et al., 1973, Hoare,1979, Andersland and Khattac,1979, Freitag,1986, Gray and Ohashi, 1983, Gray and Rafeai, 1986, Maher and Gray 1990, Maher and Ho, 1994, Michalowski and Zhao 2002, Ranjan et al. 1996, Kaniraj and Havanagi 2001, Consoli et al. 2009.

All of the papers listed above have generally shown that; strength of the soil was improved by fiber reinforcement. The investigation on clay is very limited. The purpose of this survey is to evaluate clay behaviour induced by fiber inclusion. 


\section{MATERIAL}

Composite materials consist of two parts. The first part is soil part which can be dealt as normal soil. The second part is reinforcement part which can be made up of any material which helps soil to have better performance.

\section{Soil Type}

The soil type in this study was kaolin clay. The properties of kaolin clay are presented in table 1 .

Table1. Clay properties

\begin{tabular}{ccc}
\hline No. & Type & \\
\hline 1 & Soil type & Clay \\
2 & Liquid Limit & 49 \\
3 & Plastic Limit & 23 \\
4 & Pl. Index & 26 \\
\hline
\end{tabular}

\section{Fiber Type}

The plastic fiber has been used for this investigation. The fiber properties are presented in table 2. The fiber is commercially available and is called fiber Meyco FIB SP 65 macro structural synthetic polypropylene fiber which generates a very high energy absorption rate when used in the matrix. Figure 1 shows the used fiber.

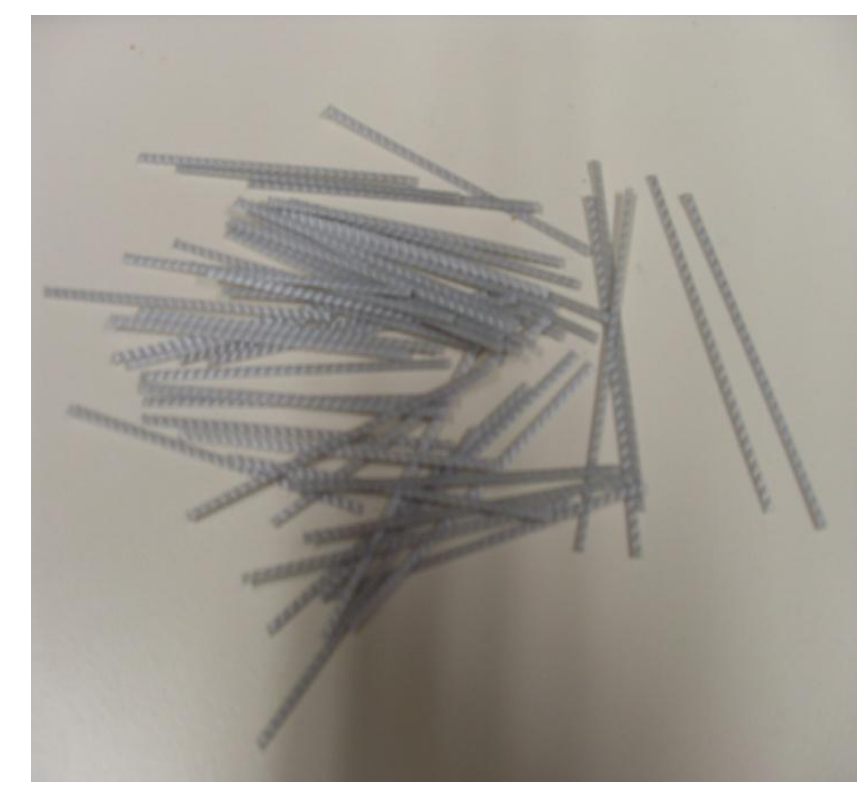

Fig. 1 Plastic fiber

Table2. fiber properties

\begin{tabular}{ccc}
\multicolumn{3}{c}{ Table2. fiber properties } \\
\hline No. & Type & \\
\hline 1 & Material & Polypropylene \\
2 & Specific Gravity & 0.92 \\
3 & Width & $1.6825 \mathrm{~mm}$ \\
& & \\
\hline
\end{tabular}




\section{TEST PROGRAM}

A series of direct shear tests have been conducted on reinforced clay composite.

\section{Direct Shear Test}

The test is carried out on either undisturbed samples or remoulded samples. To facilitate the remoulding purpose, a soil sample may be compacted at optimum moisture content in a compaction mould. Then specimen for the direct shear test could be obtained using the correct cutter provided. Alternatively, clay sample can be placed in a dry state at a required density, in the assembled shear box.

A normal load is applied to the specimen and the specimen is sheared across the predetermined horizontal plane between the two halves of the shear box. Measurements of shear load, shear displacement and normal displacement are recorded. From the results, the shear strength parameters can be determined.

\section{Equipment}

- $\quad$ Direct Shear test specimen

- Specimen preparation equipment

- Sample extruder

- fiber

- Balance

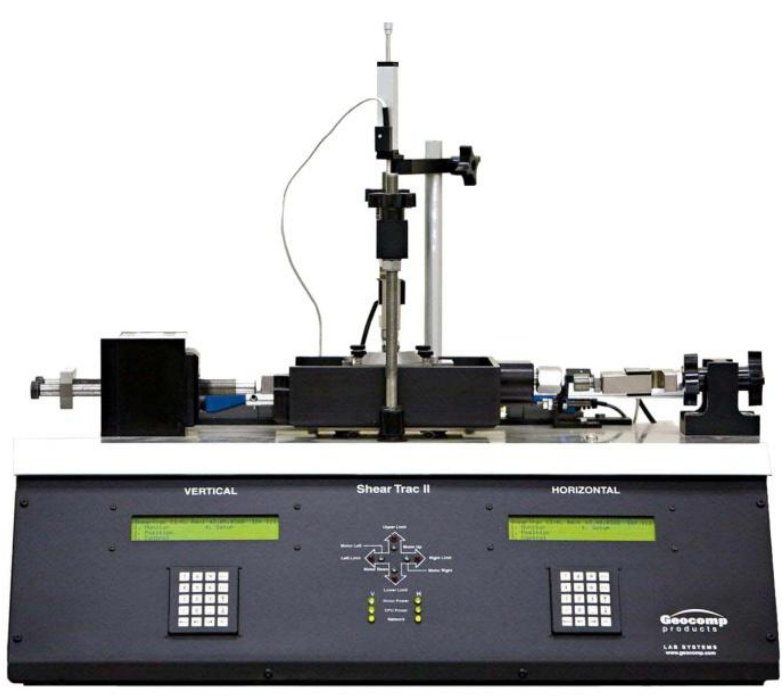

Fig. 2 Triaxial machine

\section{Sample Preparation}

The samples were prepared by mixing clay and three percentage of fiber (i.e. $0.7 \%, 1.4 \%$, and $2 \%)$. The soil was first dried under laboratory air-dried conditions then ground and passed 
through a $2 \mathrm{~mm}$ sieve. The dry powder was carefully wetted with a spray gun to the standard optimum moisture content. The moist soil was then put in sealed plastic bags in a humidity room for about two days before use. The moist residual soil was then compacted in a $300 \mathrm{~mm}$ x $300 \mathrm{~mm}$ shear box mould by machine compaction to the appropriate height and unit weight at the optimum moisture content.

\section{Test Procedure}

1. The shear box was assembled and the specimen was put into the shear box. Special care was made that the alignment screws working well.

2. The shear box was placed into the shearing device.

3. Normal load was applied to the specimen using the load transfer plate and the loading hanger.

4. Set the shearing device the advance at a rate of $0.50 \mathrm{~mm} / \mathrm{min}$.

7. The data acquisition system was run.

8. Once data acquisition has begun, the shearing device was started.

9. The Shear Stress-Displacement curve plot used for strength behavior investigation

\section{Results and Discussion}

The direct shear tests were performed in order to determine effect of fiber inclusion on shear strength of reinforced clay. Figure 4 showed the stress-displacement curve obtained from the tests at 20mm fiber length and constant normal stress of $150 \mathrm{kpa}$.

Figure 4 proved increasing in fiber content will increase the strength. Figure 5 shows the effect of fiber length on strength of composite clay at constant fiber content of $0.7 \%$ and normal stress of $150 \mathrm{kpa}$.

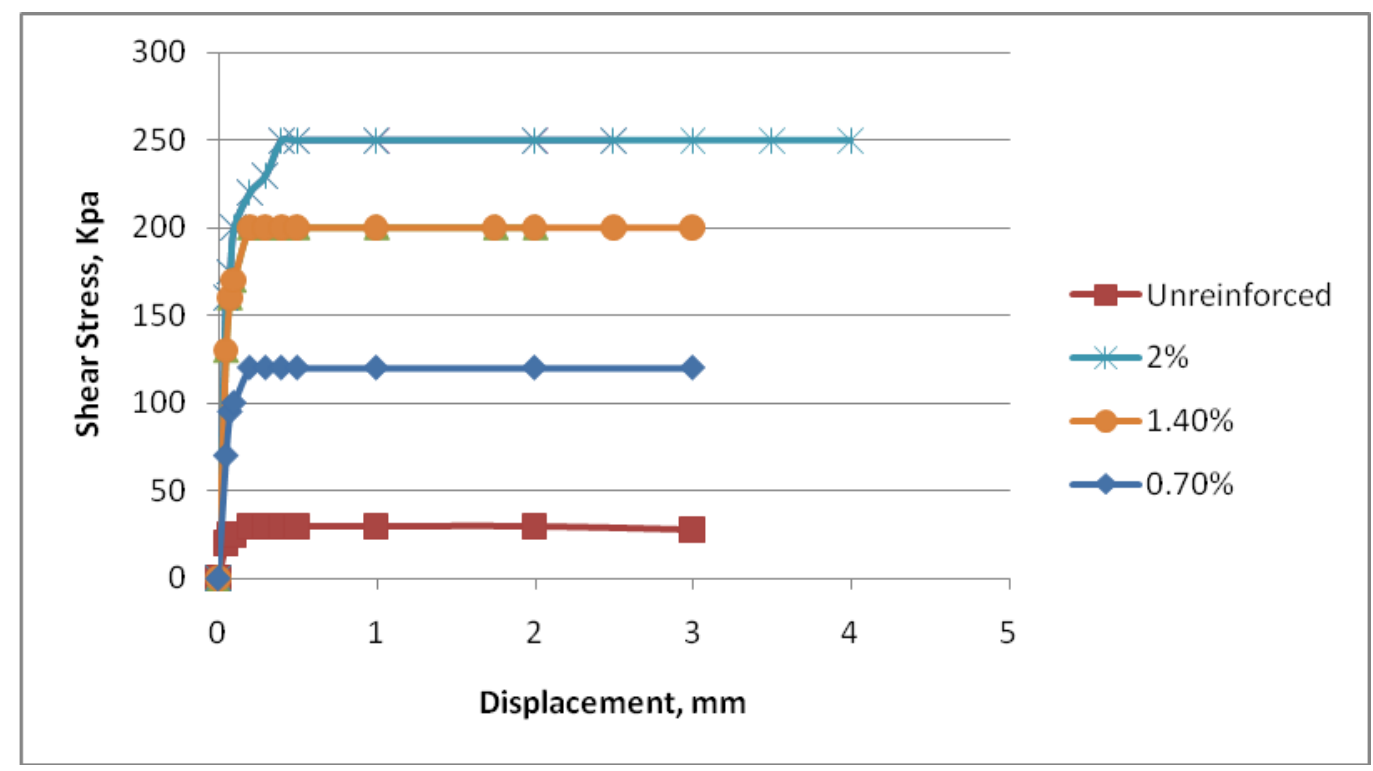

Fig. 4 Results of direct shear test in different fiber content (at 20mm, Normal stress $150 \mathrm{kpa}$ ) 


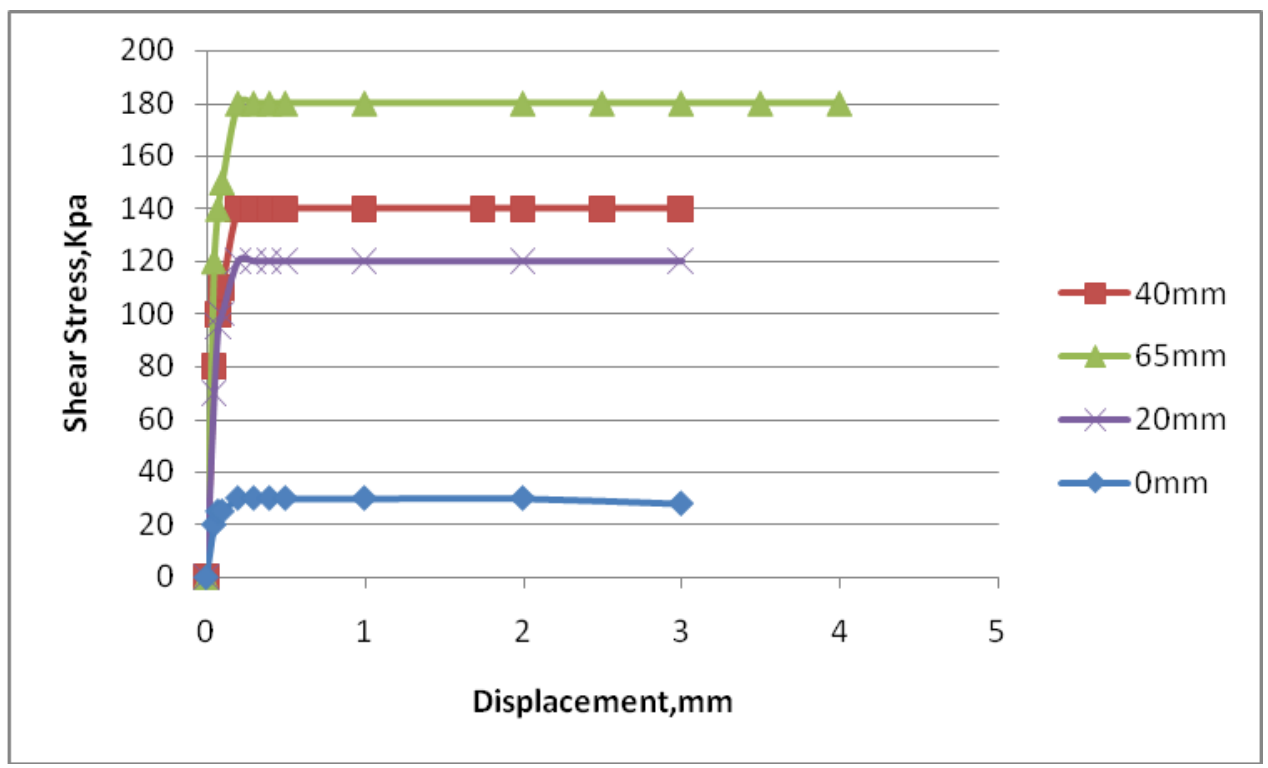

Fig. 5 Results of direct shear test in different fiber length (at $0.7 \%$ fiber content, Normal stress $150 \mathrm{kpa}$ )

\section{CONCLUSION}

The direct shear tests were conducted. Following conclusions were derived:

- Increasing in fiber percentage increased shear strength in clay samples

- During the test, it was observed that ductility behaviour of reinforced clay increased because of fiber inclusion.

- The results proved that with increasing in fiber length, the shear stress of composite clay was increased.

- Short and randomly Fiber inclusion showed to be reliable in industry projects as it helps to minimize the cost of projects.

\section{ACKNOWLEDGEMENTS}

Authors would like to thank Curtin laboratory staff for their kind assistance.

\section{REFERENCES}

[1]Akbulut, S., Arasan, S. and Kalkan, E. (2007) Modification of clayey soils using scrap tire rubber and synthetic fibers, Journal of Applied Clay Science 38, 23-32.

[2]Al Refeai, T.O. (1991) Behaviour of granular soils reinforced with discrete randomly oriented inclusions, Journal of Geotextiles and Geomembranes 10, pp. 319-333.

[3]Cai, Y., Shi, B., Charles, W.W. Ng. \& Tang, C. (2006) Effect of polypropylene fiber and lime admixture on engineering properties of clayey soil, Engineering Geology 87, $230-240$. 
[4]Consoli, N.C., Vendruscolo, M.A., Fonini, A. and Dalla Rosa, F. (2009) Fiber reinforcement effects on sand considering a wide cementation range, Geotextiles and Geomembranes 27, pp. 196-203.

[5]Freitag, D.R. (1986) Soil randomly reinforced with fibers, Journal of Geotechnical Engineering ASCE 112 (8), pp. 823-826.

[6]Lorenzo, G. A. and Bergado, D. T. (2004). Fundamental parameters of cementadmixed clay - New approach. Journal of Geotechnical and Geoenvironmental Engineering, Vol. 130, No. 10, pp. 1-9.

[7]Michalowski, R. L., Cermak, J. (2002), Strength anisotropy of fiber-reinforced sand. Computers and Geotechnics, Vol. 29, No. 4, pp. 279-299.

[8]Maher, M. H., Ho, Y. C. (1994), Mechanical-properties of kaolinite fiber soil composite. J. of Geotech. Engrg, ASCE, Vol. 120, No. 8, pp. 1381-1393.

[9]Nataraj, M. S., Mcmanis, K. L. (1997), Strength and deformation properties of soils reinforced with fibrillated fibers. Geosynthetics Int., Vol. 4, No. 1, pp. 65-79.

[10] Sivakumar Babu, G.L., Vasudevan, A.K. and Haldar, S. (2008) Numerical simulation of fiber-reinforced sand behaviour, Geotexiles and Geomembranes 26, pp. $181-188$.

[11] Yetimoglu, T. and Salbas, O. (2003) A study on shear strength of sands reinforced with randomly distributed discrete fibers, Geotextiles and Geomembranes 21 (2), pp. 103-110.

[12] Ziegler, S., Leshchinsky, D., Ling, H. I., and Perry, E. B. (1998) Effect of short polymeric fibers on crack development in clays. Soils and Foundations, Vol. 38, No. 1, pp. 247-253.

[13] Zornberg, J. G., Cabral, A. R. and Viratjandr, C. (2004) Behavior of tire shredsand mixtures, Canadian Geotechnical Journal 41 (2), pp. 227-241.

[14] Zornberg, J. G. (2002) discrete framework for limit equilibrium analysis of fiber-reinforcement, Geotechnique Journal 52 (8), pp. 227-241. 